\title{
Association of Passive Smoking with Otitis Media among School Children of Eastern Nepal
}

\author{
Manisha Paneru ${ }^{1, \odot}$ Shankar P. Shah ${ }^{2, \odot}$ Shyam Thapa Chettri ${ }^{2, \odot}$ \\ ${ }^{1}$ Department of Otorhinolaryngology and Head and Neck Surgery \\ (ORL \& HNS), Patan Academy of Health Sciences, Lalitpur, Nepal \\ ${ }^{2}$ Department of ORL \& HNS, B.P Koirala Institute of Health Sciences \\ Address for correspondence Manisha Paneru, MBBS, MS, \\ Department of ORL and HNS, Patan Academy of Health Sciences, \\ Kathmandu, 44600, Nepal (e-mail: manishapaneru@pahs.edu.np)
} (BPKIHS), Dharan, Nepal

\begin{abstract}
Keywords

- hearing loss

- otolaryngology

- otology

Introduction Otitis media (OM) and otitis media with effusion are commonly presenting conditions in an otolaryngology clinic. Exposure to passive smoking is thought to increase the risk of OM through an effect on mucociliary clearance, decreased ciliary beat frequency, or mucous hypersecretion. Awareness among parents plays a key role in the primary prevention of the disease.

Objective We aimed to identify the association of passive smoking with OM among school-going children of the eastern region of Nepal.

Methods A community-based cross-sectional study was done among 663 school-going children, selected by stratified random sampling using a questionnaire. Data regarding age, gender, type of school, otological symptoms, smoking status of parents and family members, otoscopic findings, pure tone audiometry, and impedance audiometry were recorded.

Results Six-hundred and sixty-three students were included in the study. OM was confirmed in 103 students (15.5\%). Smoking history was present in at least one of the family members in 177 out of 663 students (26.69\%) and with positive smoking history in any member of the family, OM was seen in $65(36.7 \%)$ students $(p \leq 0.001)$, which suggested significant association. OM was seen in 38 students $(7.8 \%)$ when there was no exposure to passive smoking.

Conclusions There is a high prevalence of OM (15.5\%) in school-going children. The study shows significant association between passive smoking and OM in children.
\end{abstract}

\section{Introduction}

Otitis media $(\mathrm{OM})$ is a broad term referring to inflammation of the middle ear cleft, with or without effusion. Acute otitis media (AOM) is characterized by rapid onset of signs and symptoms, such as otalgia and fever. Likewise, otitis media with effusion (OME) refers to nonpurulent fluid in the middle ear space, often occurring as a result of previous infection

Published online September 24, 2021
DOI https://doi.org/ $10.1055 / \mathrm{s}-0041-1735395$ ISSN 2581-9607 when there are no clinical features of acute infection and without perforation of the tympanic membrane. ${ }^{1}$ Hippocrates in $450 \mathrm{BC}$ was first to describe $\mathrm{OM}$ and it continues to present itself even today as one of the most inexplicable universally observed medical problems of childhood and a leading cause of hearing loss among them. ${ }^{2}$

OM is estimated to affect over $90 \%$ of children before their second birthday. ${ }^{1}$ Within the Unites States, half of the

\footnotetext{
(C) 2021. Indian Society of Otology.

This is an open access article published by Thieme under the terms of the Creative Commons Attribution-NonDerivative-NonCommercial-License, permitting copying and reproduction so long as the original work is given appropriate credit. Contents may not be used for commercial purposes, or adapted, remixed, transformed or built upon. (https://creativecommons.org/licenses/by-nc-nd/4.0/).

Thieme Medical and Scientific Publishers Pvt. Ltd. A-12, 2nd Floor, Sector 2, Noida-201301 UP, India
} 
children are diagnosed with OM before their first birthday, and 9 out of 10 children are diagnosed by their fifth birthday. ${ }^{3}$ OME is most prevalent under the age of 7 years. ${ }^{4}$

A wide variety of risk factors have been documented for causation of OM. These are characterized into three groups: host factors (sex, age, racial, social, cultural, hygiene, nutrition, family history, immunological, physiological and pathological differences), environmental factors (climatic, seasonal, housing, crowding, and schooling), and etiological factors (microorganisms, toxic substances, and allergens). ${ }^{4}$

Exposure to smoke is a potential risk factor in the development of $\mathrm{OM}$ and has gained considerable attention in the recent times. Smoking either in active or passive form is a potential risk factor and certainly increases the risk of respiratory tract infections and few invasive diseases mostly among adults. ${ }^{5}$ Among children, passive smoking is mostly associated with upper and lower respiratory tract infections, such as AOM, pneumonia, and respiratory bronchitis. ${ }^{6}$ Several studies have shown that passive smoking is associated with increased prevalence of OM. ${ }^{7}$ Various pathophysiologies have been explained for passive smoking and most explainable one is smoke either from active or passive form increases bacteria adherence to the respiratory epithelium, depresses local immune function, decreases mucociliary action of respiratory epithelium, and hence is a potential risk factor for OM development. ${ }^{8}$

The clinical course of OM, recurrent OM and its squeal is varied. There may be spontaneous resolution of symptoms without any adverse effect, while few children may eventually require some medical attention, be it in form of medications or surgical intervention (myringotomy and tympanostomy tubes). ${ }^{9}$ Unfortunately, many children will still experience recurrent and more severe episodes of the disease that eventually lead to decreased hearing. ${ }^{10}$

Among many health-related challenges, ear disease and decreased hearing still remain major health concerns in most of the developing countries. In 1993, hearing impairment and ear pathology assessment was done in eastern and mid-western part of Nepal in which $16.6 \%$ of the study population had hearing impairment and $7.4 \%$ had ear drum pathology, equivalent to, respectively, 2.71 and 1.48 million people extrapolated to the whole of Nepal. ${ }^{11}$ Likewise, a prospective cross-sectional study in the year 2009 among the children of age group 5 to 13 showed prevalence of chronic suppurative otitis media to be $7.6 \%$ and OME to be $4.7 \% .^{12}$

All studies do not establish an association between environmental tobacco smoke (ETS) and middle ear disease. Kitchens did a prospective cohort study to determine if ETS is an etiological factor in OM. Its results revealed that the case group commonly had exposure to ETS $(p=0.04$ ). However, there was no significant difference in the clinical course of the children who were exposed to ETS and those who were not. ${ }^{13}$

Despite the high prevalence of OM in the pediatric population and its underlying risk factors, no studies have been conducted in Nepal on the association of passive smoking and OM. Changing the study setting from clinics to the community will help in broader and better understanding of the disease and its associated factors. Complete understanding of the disease burden in community settings will help in better planning and formulation of community level interventions.

\section{Methods}

A community-based cross-sectional study was conducted in the Montessori and primary schools of a submetropolitan city in Eastern part of Nepal. The data for this study was collected in the period between February 2018 and February 2019. Ethical approval was obtained from the Institutional Ethical Review Board (Ref No: 310/074/075-IRC). Informed and written consent was taken prior to study.

\section{Study Population}

This is a prospective cross-sectional study among school children (Montessori, private, and government) aged between 3 and 12 years. Children with URTI at the time of examination, syndromic children, otitis externa, osteoma, ear wax, and environmental smoke exposure were excluded from the study.

\section{Sampling Technique}

Stratified random sampling was done to obtain representative sample. The proportion was based on total number of Montessori (preschool), private, and government schools. A list of all Montessori, primary, and government school was obtained from district education office. The list consisted of the name of the schools and their codes. Then, using random method, two government schools, two private schools, and two Montessori schools were selected.

A prior appointment with the head of the selected school was arranged who was then explained about the study. Once the permission was granted, a visit to the school was then made on the day of study. The questionaries with the informed consent were distributed to the students and asked to be filled up by the parents and on the following day school was revisited and examinations of the students were done. Appropriate tools and techniques were used to collect the data on the day. In case the data collection was incomplete, subsequent visits to the school were made on convenient time.

In case of abnormal otoscopic findings suggestive of acute or chronic OM, OME, and/or hearing loss, the children were further evaluated and investigated in the hospital clinic with play audiometry (3-5 years of age) or pure tone audiometry (> 5 years of age) (Madsen Orbiter 922, GN Otometrics $\mathrm{A} / \mathrm{S}$, Copenhagen, Denmark) and impedance tympanometry (Madsen Zodiac 901, GN Otometrics A/S, Copenhagen, Denmark).

\section{Identification of Children with Otitis Media}

AOM was considered when there was redness, bulging or perforation with or without discharge in the tympanic membrane.

Chronic OM was considered when there was perforation, retraction, with or without ear discharge, or cholesteatoma. 
OME was considered when tympanic membrane was dull lusterless, foreshortened handle of malleus, prominent short process or bluish tympanic membrane, and type B curve on impedance tympanometry.

Confirmed OM was considered when OM (AOM, OME) in either form was confirmed with type B curve in impedance audiometry.

\section{Tools of Passive Smoking}

Smoking by family member residing in the same house and having close contact with child in any form (bidi, pipe, cigar, and cigarette).

\section{Audiogram and Impedance Audiometry}

All the children were evaluated on the day of study after reviewing the questionaries filled by their parents. Children were then categorized accordingly if they were normal or having $\mathrm{OM}$ on the basis of handheld otoscope. In case of abnormal otoscopic findings suggestive of OM, chronic OM, OME, and/or hearing loss, the children were further evaluated in ENT OPD and were further evaluated with play audiometry (3-5 years of age) or pure tone audiometry ( $>5$ years of age) (Madsen Orbiter 922) and impedance tympanometry (Madsen Zodiac 901) in the required cases.

\section{Data Management and Statistical Analysis}

Data was entered in Microsoft Excel and converted into Statistical Package for Social Sciences for Statistical Analysis (11.5). Alpha numerical codes were used. For descriptive statistics, data were presented in percentage, mean, and standard deviation (SD) and summarized using frequency distribution tables and graphical methods of presentation. For inferential statistics, bivariate analysis was done using appropriate test of significance (chi-square test, Student's t-test). Univariate binary logistic regression was done to calculate the crude odds ratio for the independent factors. Multivariate binary logistic regression was done to find the adjusted odds ratio. Statistical significance was tested with $95 \%$ confidence interval and $p$-value $<0.05$ was considered as significant.

\section{Result}

The study included 663 students studying in Montessori, private, and government school. The age ranged from 3 to 12 years and the mean age was 7.84 years $(S D=2.772)$. Male students (50.7\%) slightly outnumbered the females (49.2\%) in this study (- Table 1). Equal number of students (221) were selected from the categorized three different schools (Montessori, private, and government).

Nearly one-fifth of the fathers smoked (20.2\%), 2.3\% of mothers smoked and few other family members smoked (8.7\%) like grandparents, uncle, and aunts living together as joint family. The member smoked from a maximum of 7 to a minimum of 1 cigarette per day (-Fig. 1 ).

The ears of all the students were examined with a handheld otoscope. Among the four characteristics of the OM (redness, discharge, perforation, and retraction), maximum students had retraction in both of the ears (right-13.3\%, left-12.2\%) (- Table 2).

Based on the otoscopic findings, 106 students were investigated with pure tone audiometry and/or tympanometry as indicated.

Among the investigated ears, conductive hearing loss was detected among 9.5\% on right ear and 10.4\% on left ear. Frequency of normal hearing among the investigated ear was $6.5 \%$ and $5.6 \%$, respectively, on right and left ear.

On performing impedance audiometry, B curve was seen in $7.8 \%$ (right) and $7.1 \%$ (left) of the investigated ears suggesting OME among the clinically suspected cases of the OM. Likewise, A curve was seen on $4.7 \%$ (right) and 5.6\% (left) and C curve was seen on $0.6 \%$ right and $0.5 \%$ left ears ( - Table 3 ;

-Figs. 2 and 3 ).

OM was seen in $12.7 \%$ of those younger than 6 years and $16.5 \%$ in those aged 6 years and older. Similarly, males had more OM (15.1\%) compared to females (16.0\%). Those

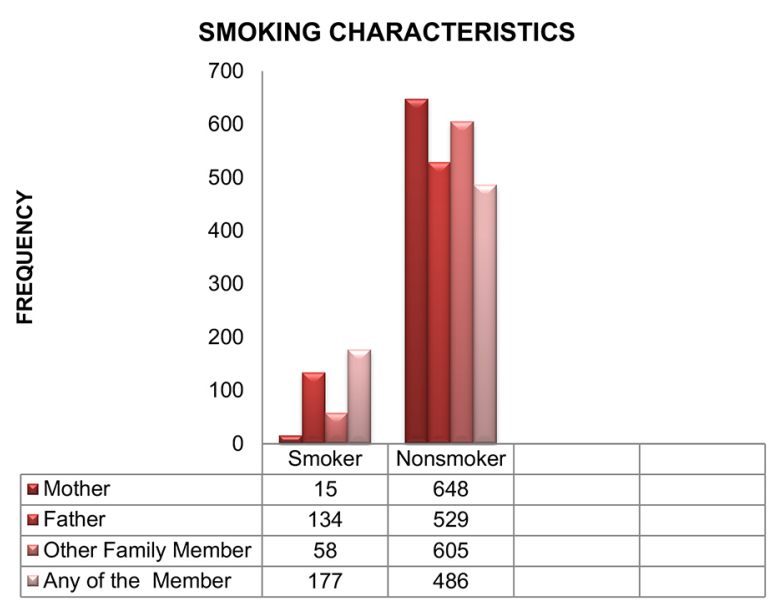

Fig. 1 Distribution of the smoking characteristics among the family members.

Table 1 Distribution of participants according to age groups, sex ( $n=663$ )

\begin{tabular}{|l|l|l|l|}
\hline Characteristics & Category & Frequency & Percentage \\
\hline \multirow{2}{*}{ Age } & $<6$ years & 166 & 25.0 \\
\cline { 2 - 4 } & $\geq 6$ years & 497 & 75.0 \\
\hline \multirow{2}{*}{ Mean \pm SD (min, max) } & \multicolumn{2}{|c|}{$7.84 \pm 2.722(3,12)$} \\
\hline \multirow{2}{*}{ Sex } & Female & 326 & 49.2 \\
\cline { 2 - 4 } & Male & 337 & 50.8 \\
\hline
\end{tabular}

Abbreviation: SD, standard deviation. 
studying in government school had highest prevalence of OM (20.8\%) in compared to children in Montessori schools (15.4\%), while $10.4 \%$ of private school students had prevalence of OM. OM was found to have statistically significant association with type of schools.

The prevalence of OM was $36.7 \%$ when smoking was present in any of the family members. The prevalence of the OM was $73.3 \%$ when there was smoking habit in the mother, whereas prevalence was $35.8 \%$ when smoking habit was present in father and comparatively less when smoking habit in other family member (34.5\%). OM was found to have statistically significant association with passive smoking among parents and family members as shown in - Tables 4 and 5.

\section{Multivariable Analysis of the Associated Factors}

The independent variables that were found to be associated with $\mathrm{OM}$ at $p$-value less than 0.1 were taken for multivariable analysis. Binomial logistic regression was done using ENTER method. There were five variables associated at $p<0.1$, which were school type, mother's literacy, smoking in mother, smoking in father, and smoking in other members. These five variables were included as covariate in logistic regression, with confirmed OM as the dependent factor.

Even after adjustment, in government school, smoking in mother, smoking in father, and smoking in other members were found to be associated significantly $(p<0.05)$. The different variables, with their respective $\beta$-coefficient, adjusted odd's ratio along with its $95 \%$ confidence interval have been mentioned in - Table 6.

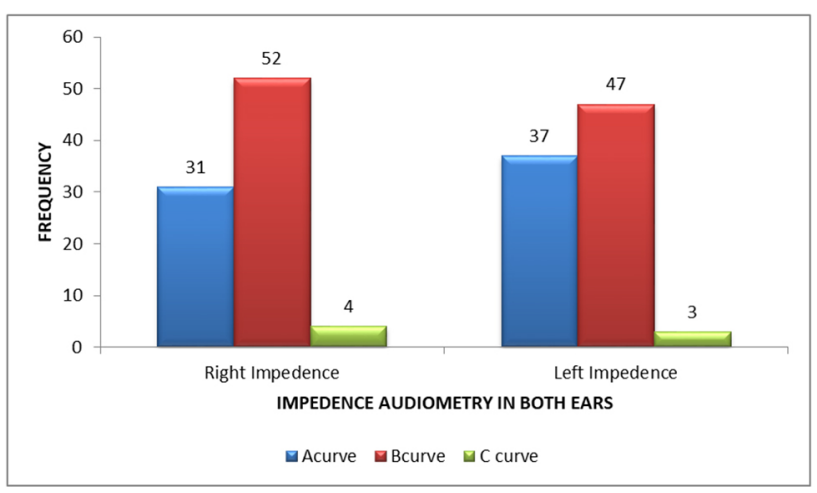

Fig. 2 Distribution of the impedance audiometry among the students in both ears.

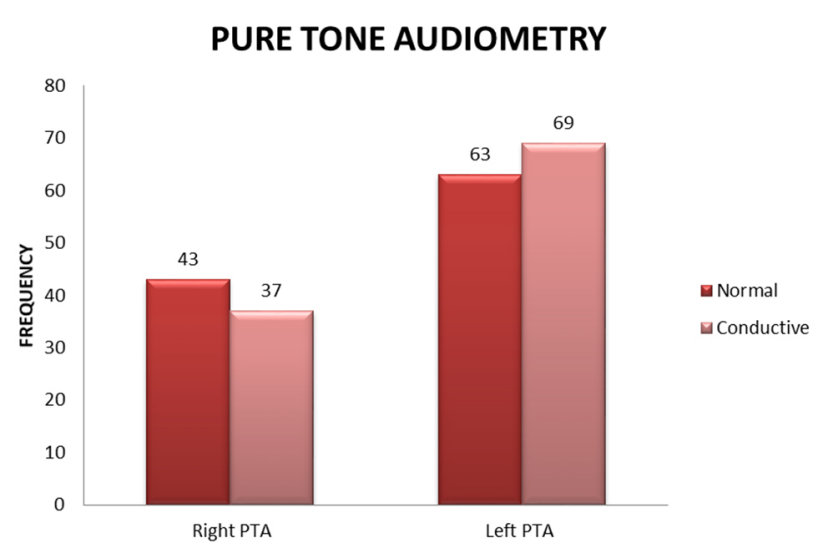

Fig. 3 Distribution of pure tone audiometry (PTA) among the students in the clinically suspected cases of otitis media.

Table 2 Distribution of otoscopic findings in both ear $(n=663)$

\begin{tabular}{|l|l|l|l|l|l|}
\hline \multirow{2}{*}{ Characteristics } & \multirow{2}{*}{ Category } & \multicolumn{2}{|c|}{ Right ear } & \multicolumn{2}{c|}{ Left ear } \\
\cline { 3 - 6 } & & Frequency & Percentage & Frequency & Percentage \\
\hline \multirow{2}{*}{ Redness } & Present & 4 & 0.6 & 5 & 0.8 \\
\cline { 2 - 6 } & Absent & 659 & 99.4 & 658 & 99.2 \\
\hline \multirow{2}{*}{ Discharge } & Present & 4 & 0.6 & 6 & 0.9 \\
\cline { 2 - 7 } & Absent & 659 & 99.4 & 657 & 99.1 \\
\hline Perforation & Present & 8 & 1.2 & 18 & 2.7 \\
\cline { 2 - 6 } & Absent & 655 & 98.8 & 645 & 97.3 \\
\hline Retraction & Present & 88 & 13.3 & 81 & 12.2 \\
\cline { 2 - 6 } & Absent & 575 & 86.7 & 582 & 87.8 \\
\hline
\end{tabular}

Table 3 Results of audiological Investigation among students $(n=663)$

\begin{tabular}{|c|c|c|c|c|c|}
\hline \multirow[t]{2}{*}{ Investigations } & \multirow[t]{2}{*}{ Category } & \multicolumn{2}{|c|}{ Right ear } & \multicolumn{2}{|c|}{ Left ear } \\
\hline & & Frequency & Percentage & Frequency & Percentage \\
\hline \multirow[t]{4}{*}{ Impedance } & A curve & 31 & 4.7 & 37 & 5.6 \\
\hline & B curve & 52 & 7.8 & 47 & 7.1 \\
\hline & C curve & 4 & 0.6 & 3 & 0.5 \\
\hline & Total & 87 & 13.1 & 87 & 13.1 \\
\hline \multirow[t]{3}{*}{ Pure tone audiometry } & Normal & 43 & 6.5 & 37 & 5.6 \\
\hline & Conductive & 63 & 9.5 & 69 & 10.4 \\
\hline & Total & 106 & 16.0 & 106 & 16.0 \\
\hline
\end{tabular}


Table 4 Association of otitis media with sociodemographic characters

\begin{tabular}{|c|c|c|c|c|c|}
\hline \multirow[t]{2}{*}{ Characteristics } & \multirow[t]{2}{*}{ Category } & \multicolumn{2}{|c|}{ Otitis media } & \multirow[t]{2}{*}{ Total } & \multirow[t]{2}{*}{$p$-Value } \\
\hline & & Yes (\%) & No (\%) & & \\
\hline \multirow[t]{2}{*}{ Age } & $<6 y$ & $21(12.7)$ & $145(87.3)$ & 166 & \multirow[t]{2}{*}{0.236} \\
\hline & $\geq 6 y$ & $82(16.5)$ & $415(83.5)$ & 497 & \\
\hline \multirow[t]{2}{*}{ Gender } & Male & $51(15.1)$ & $286(84.9)$ & 337 & \multirow[t]{2}{*}{0.771} \\
\hline & Female & $52(16.0)$ & $274(84.0)$ & 326 & \\
\hline \multirow[t]{3}{*}{ School } & Montessori & $34(15.4)$ & $187(84.6)$ & 221 & \multirow[t]{3}{*}{0.010} \\
\hline & Private & $23(10.4)$ & $198(89.6)$ & 221 & \\
\hline & Government & $46(20.8)$ & $175(79.2)$ & 221 & \\
\hline
\end{tabular}

Table 5 Association of passive smoking with otitis media $(n=663)$

\begin{tabular}{|c|c|c|c|c|c|}
\hline \multirow[t]{2}{*}{ Characteristics } & \multirow[t]{2}{*}{ Category } & \multicolumn{2}{|c|}{ Otitis media } & \multirow[t]{2}{*}{ Total } & \multirow[t]{2}{*}{$p$-Value } \\
\hline & & Yes (\%) & No (\%) & & \\
\hline \multirow[t]{2}{*}{ Smoking in any members } & Yes & $65(36.7)$ & $112(63.3)$ & 177 & \multirow[t]{2}{*}{$<0.001$} \\
\hline & No & $38(7.8)$ & $448(92.2)$ & 486 & \\
\hline \multirow[t]{2}{*}{ Smoking mother } & Yes & $11(73.3)$ & $4(26.7)$ & 15 & \multirow[t]{2}{*}{$<0.001^{\mathrm{a}}$} \\
\hline & No & $92(14.2)$ & $556(85.8)$ & 648 & \\
\hline \multirow[t]{2}{*}{ Smoking father } & Yes & $48(35.8)$ & $86(64.2)$ & 134 & \multirow[t]{2}{*}{$<0.001$} \\
\hline & No & $55(10.4)$ & $474(89.6)$ & 529 & \\
\hline \multirow[t]{2}{*}{ Smoking other members } & Yes & $20(34.5)$ & $38(65.5)$ & 58 & \multirow[t]{2}{*}{$<0.001$} \\
\hline & No & $83(13.7)$ & $522(86.3)$ & 605 & \\
\hline
\end{tabular}

Fisher's exact test applied.

\section{Discussion}

$\mathrm{OM}$ is a common disease among the children and adults. Various etiologies and risk factors have been identified and studied for its causation. Among many risk factors passive smoking is also considered to be one of them. However, there has been conflicting results among the various studies in the past for it to be considered as a risk factor.

In our study, OM was clinically diagnosed among 126 students (19\%) and confirmed with investigations in 103 students (15.5\%). Smoking among mother, father, and other family members were seen in 15 (2.3\%), 134 (20.2\%), and 58 (8.7\%) of the total students, respectively. When smoking history was present in one of the parent and/or family member, OM was seen in 65 (36.7\%), which showed statistically significant association $(p<0.001)$. However, OM was seen in $7.8 \%$ of students when there was no associated smoking history in either parent and or a family member.

\section{Sociodemographic Characteristics Age Group}

In this study, mean age of the participants was 7.84 years $(\mathrm{SD}=2.72$ ) and it ranged from 3 to 12 years of age. Various literatures in which school-based studies were done to determine the prevalence of OM included the similar age group as of the present study. In the present study, OM was more prevalent among children more than 6 years of age group. However, in a prospective study conducted among the school-going children in Kenya by Simões et al the prevalence of AOM and OME was highest in children under the age of 6 years and steadily declined as children got older. ${ }^{14}$

\section{Gender}

There was higher proportion of males (50.8\%) than females (49.2\%) in this study that was similar to a cross-sectional community-based survey conducted among school-going children in Yemen, which had higher proportion of males (54.4\%) ${ }^{15}$ However, the prevalence of OM was more in the female children (16.0\%) compared to male children (15.1\%) in our study that was similar to the cross-sectional study conducted in Bangladesh where girls were relatively more sufferer than boys ( 6.6 vs. $4.5 \%$ ), which may be due to higher female population in the study group in comparison to the male. ${ }^{16}$

\section{School Distribution}

In our study, we had equal division of the school (i.e., two Montessori, two private, and two governments schools). The prevalence of OM was higher in the government school (20.8\%) in comparison to the Montessori (15.4\%) and private school (10.4\%). Contradictory to our study, a prospective cross-sectional study done in urban private school of Nepal showed that the prevalence of CSOM in children studying in urban private schools of Nepal was 5.0\%. This study showed that the prevalence of CSOM was lower in government school children of Nepal contrary to our study probably due to the study done in the urban setting where there is a good socioeconomic status, good sanitation, better housing condition, 
Table 6 Multivariable analysis of the associated factors

\begin{tabular}{|c|c|c|c|c|c|c|c|}
\hline \multirow[t]{2}{*}{ Variables } & \multirow[t]{2}{*}{ Categories } & \multirow{2}{*}{$\begin{array}{l}\text { Beta } \\
\text { coefficient }\end{array}$} & \multirow{2}{*}{$\begin{array}{l}\text { Standard } \\
\text { error }\end{array}$} & \multirow[t]{2}{*}{$p$-Value } & \multirow{2}{*}{$\begin{array}{l}\text { Adjusted } \\
\text { odds ratio }\end{array}$} & \multicolumn{2}{|c|}{$95 \% \mathrm{Cl}$ for aOR } \\
\hline & & & & & & Lower & Upper \\
\hline \multirow[t]{3}{*}{ School } & Private & \multicolumn{4}{|c|}{ Reference } & & \\
\hline & Montessori & 0.209 & 0.333 & 0.529 & 1.233 & 0.642 & 2.367 \\
\hline & Government & 0.686 & 0.349 & 0.049 & 1.987 & 1.002 & 3.939 \\
\hline \multirow{2}{*}{$\begin{array}{l}\text { Literacy of } \\
\text { mother }\end{array}$} & Illiterate & \multicolumn{3}{|c|}{ Reference } & & & \\
\hline & Literate & -0.143 & 0.281 & 0.612 & 0.867 & 0.500 & 1.504 \\
\hline \multirow{2}{*}{$\begin{array}{l}\text { Smoking in } \\
\text { mother }\end{array}$} & No & \multicolumn{3}{|c|}{ Reference } & & & \\
\hline & Yes & 2.410 & 0.635 & 0.000 & 11.134 & 3.206 & 38.668 \\
\hline \multirow{2}{*}{$\begin{array}{l}\text { Smoking in } \\
\text { father }\end{array}$} & No & \multicolumn{4}{|c|}{ Reference } & & \\
\hline & Yes & 1.343 & 0.245 & 0.000 & 3.829 & 2.368 & 6.193 \\
\hline \multirow{2}{*}{$\begin{array}{l}\text { Smoking } \\
\text { in other } \\
\text { members }\end{array}$} & No & \multicolumn{4}{|c|}{ Reference } & & \\
\hline & Yes & 1.015 & 0.327 & 0.002 & 2.758 & 1.453 & 5.235 \\
\hline Constant & & -2.573 & 0.246 & 0.000 & 0.076 & & \\
\hline
\end{tabular}

Abbreviations: aOR, adjusted odds ratio; $\mathrm{Cl}$, confidence interval.

and better health care facilities as compared with the government school in rural settings. ${ }^{12}$

\section{Smoking and Otitis Media}

The present study had a prevalence of OM of $36.7 \%$ among children if any member smoked and it was statistically significant $(p \leq 0.001)$.

The prevalence of OM when only mother, father and other family members smoked was $73.3,35.8$, and $34.5 \%$, respectively, and all of it were statistically significant $(p \leq 0.001)$. The result of this study is similar to that of Jacoby et al who had conducted a prospective cohort study on the effect of passive smoking on the risk of OM in Aboriginal and non-Aboriginal children in western Australia and had also supported that passive smoking is a risk factor of OM. Sixty-four percent of Aboriginal children and $40 \%$ of non-Aboriginal children were exposed to ETS. Tympanometry was performed on 87 Aboriginal and 168 non-Aboriginal children; a type B tympanogram (suggesting fluid in the middle ear) was also associated with passive smoking in Aboriginal children. ${ }^{17}$

Likewise, various studies have supported a parental smoking as a risk factor for OM among children. Similarly, an epidemiological prospective study was done in a day care institution to see the association of indoor environment and middle ear effusion (MEE). With the exception of parental smoking, none of the environmental factors $\left(\mathrm{CO}_{2}\right.$, temperature, and relative humidity) showed a tendency to influence the prevalence of MEE. ${ }^{18}$

However, in the present study even after adjustment, government school, smoking in mother, smoking in father, and smoking in other members were found to be associated significantly $(p<0.05)$.

In contrast, Kero and Piekkela investigated AOM and recurrent otitis media in 5,356 children and did not find an association between parental smoking and middle ear disease. However, they studied children aged 1 year and younger. Furthermore, they studied not only OME but also AOM and
OME together. ${ }^{19}$ Perhaps the time taken for the mucociliary dysfunction to the pathogenesis of $\mathrm{OM}$ is longer.

\section{Conclusion}

There was a high prevalence of OM (15.5\%) in school-going children in the eastern part. A higher prevalence of OM was seen in the children who were exposed to the passive smoking as compared with children not exposed to passive smoking. Therefore, an association can also be drawn between the $\mathrm{OM}$ and those exposed to passive smoking. A higher prevalence of OM was seen among the school children attending government school as compared to those attending the Montessori and private school.

\section{Availability of Data and Materials}

The dataset(s) supporting the conclusions of this article is(are) included within the article (and its additional file(s)).

\section{Funding}

This research received no specific grant from any funding agency, commercial or not-for-profit sectors.

\section{Conflict of Interest}

The authors declare that they have no competing interests.

\section{Acknowledgments}

The authors would like to thank all the principals, class teachers, parents, and students of all those schools enrolled in this study. Authors would also like to thank faculties, residents, and audiologist who provided support to this study.

\section{References}

1 Paradise JL, Rockette HE, Colborn DK, et al. Otitis media in 2253 Pittsburgh-area infants: prevalence and risk factors during the first two years of life. Pediatrics 1997;99(3):318-333 
2 Maharjan M, Bhandari S, Singh I, Mishra SC. Prevalence of otitis media in school going children in Eastern Nepal. Kathmandu Univ Med J (KUMJ 2006;4(4):479-482 (KUMJ)

3 Teele DW, Klein JO, Rosner B. Epidemiology of otitis media during the first seven years of life in children in greater Boston: a prospective, cohort study. J Infect Dis 1989;160(1):83-94

4 Maw AR, Bawden R. Factors affecting resolution of otitis media with effusion in children. Clin Otolaryngol Allied Sci 1994;19(2):125-130

5 DiFranza JR, Aligne CA, Weitzman M. Prenatal and postnatal environmental tobacco smoke exposure and children's health. Pediatrics 2004;113(4(Suppl):1007-1015

6 Lanari M, Giovannini M, Giuffré L, et al; Investigators R.A.DA.R. Study Group. Prevalence of respiratory syncytial virus infection in Italian infants hospitalized for acute lower respiratory tract infections, and association between respiratory syncytial virus infection risk factors and disease severity. Pediatr Pulmonol 2002;33(6):458-465

7 Yolton K, Dietrich K, Auinger P, Lanphear BP, Hornung R. Exposure to environmental tobacco smoke and cognitive abilities among U.S. children and adolescents. Environ Health Perspect 2005;113(1):98-103

8 Carter BD, Abnet CC, Feskanich D, et al. Smoking and mortalitybeyond established causes. N Engl J Med 2015;372(7):631-640

9 Qureishi A, Lee Y, Belfield K, Birchall JP, Daniel M. Update on otitis media - prevention and treatment. Infect Drug Resist 2014;7:15-24

10 Brennan-Jones CG, Whitehouse AJ, Park J, et al. Prevalence and risk factors for parent-reported recurrent otitis media during early childhood in the Western Australian Pregnancy Cohort (Raine) Study. J Paediatr Child Health 2015;51(4):403-409
11 Little P, Bridges A, Guragain R, Friedman D, Prasad R, Weir N. Hearing impairment and ear pathology in Nepal. J Laryngol Otol 1993;107(5):395-400

12 Adhikari P. Pattern of ear diseases in rural school children: experiences of free health camps in Nepal. Int J Pediatr Otorhinolaryngol 2009;73(9):1278-1280

13 Kitchens GG. Relationship of environmental tobacco smoke to otitis media in young children. Laryngoscope 1995;105(5 Pt 2, Suppl 69) :1-13

14 Simões EA, Kiio F, Carosone-Link PJ, Ndegwa SN, Ayugi J, Macharia IM. Otitis media and its sequelae in Kenyan schoolchildren. J Pediatric Infect Dis Soc 2016;5(4):375-384

15 Muftah S, Mackenzie I, Faragher B, Brabin B. Prevalence of chronic suppurative otitis media (CSOM) and associated hearing impairment among school-aged children in Yemen. Oman Med J 2015;30(5):358-365

16 Shaheen MM, Raquib A, Ahmad SM. Prevalence and associated socio-demographic factors of chronic suppurative otitis media among rural primary school children of Bangladesh. Int J Pediatr Otorhinolaryngol 2012;76(8):1201-1204

17 Jacoby PA, Coates HL, Arumugaswamy A, et al. The effect of passive smoking on the risk of otitis media in Aboriginal and non-Aboriginal children in the Kalgoorlie-Boulder region of Western Australia. Med J Aust 2008;188(10):599-603

18 Pukander J, Luotonen J, Timonen M, Karma P. Risk factors affecting the occurrence of acute otitis media among 2-3-year-old urban children. Acta Otolaryngol 1985;100(3-4):260-265

19 Kero P, Piekkala P. Factors affecting the occurrence of acute otitis media during the first year of life. Acta Paediatr Scand 1987;76(4):618-623 